\title{
Quality of Life: How Do Adolescents With Facial Differences Compare With Other Adolescents?
}

\author{
TARI D. TOPOLSKI, Ph.D. \\ TODD C. EdWARDS, PH.D. \\ Donald L. Patrick, Ph.D., M.S.P.H.
}

\begin{abstract}
Objective: Compare the quality of life (QOL) of youth living with visible facial differences (FDs) with youth living with a visible nonfacial difference (i.e., mobility limitations), an invisible difference (i.e., attention deficit/hyperactivity disorder), or no known difference.

Design: An observational study of perceived QOL among adolescents with FDs $(n=56)$, adolescents with no diagnosed chronic condition (NCC, $n=116)$, adolescents with mobility limitations $(M L, n=52)$, and adolescents with attention deficit/hyperactivity disorder (ADHD, $n=68$ ).

Participants: Adolescents ages 11-18 years with FDs recruited through Children's Hospital, Seattle, Washington, participated in this study. Comparison groups were from a previous study of QOL among youth with and without chronic conditions.

Main Outcome Measures: The main outcome measure was the Youth Quality of Life Instrument-Research Version, a generic instrument that assesses both perceptual and contextual aspects of QOL in four domains: Sense of Self, Relationships, Environment/Culture, and General Quality of Life.

Results: A MANCOVA adjusting for age, gender, and depressive symptomatology revealed that adolescents with FDs, on average, reported significantly lower overall QOL than did the NCC group. Their domain scores were similar to those of the other chronic conditions groups on all but the relationship domain. Reviewing the constituent items of the relationship domain revealed that adolescents in the ML and FDs groups reported higher scores than either the NCC group or the ADHD group on the relationship variables concerning family.

Conclusions: Adolescents with facial differences confront significant challenges to their own self-identity while experiencing higher QOL from relationships, possibly from their need to negotiate and maintain close family support.
\end{abstract}

KEY WORDS: adolescence, facial differences, quality of life

For youth with both congenital (Padwa et al., 1991) and acquired facial differences (FDs) (McQuaid et al., 2000), adolescence is a critical time. The youth must not only navigate the normative developmental tasks of this period, but must do so while dealing with the effect of their condition on their appearance and sense of self. Because of the centrality of the face in human interactions and development, facial differences may be particularly stigmatizing (Cole, 1998). Studies regarding nondisabled youths' attitudes toward youth with disabilities show that nondisabled youths prefer those with mobility limitations to those with facial differences (Harper et al., 1986;

Dr. Topolski and Dr. Edwards are Affiliate Assistant Professors in the Department of Health Services at the University of Washington. Dr. Patrick is a Professor in the Department of Health Services at the University of Washington. Submitted July 2003; Accepted July 2004.

Address correspondence to: Dr. Tari D. Topolski, University of Washington, Seattle Quality of Life Group, 146 N. Canal Street Suite 313, Seattle, WA 91803. E-mail topolski@u.washington.edu.
Harper, 1995). Stigmatizing social responses to speech impairment or facial differences may lead to negative self-perceptions of competence and physical attractiveness (Kapp-Simon et al., 1992). Stigmatization of youth, be it related to a visible difference such as a mobility limitation or a facial difference, or to an invisible difference such as having an emotional or behavioral problem such as attention deficit/hyperactivity disorder, may result in a negative effect on a youth's quality of life (QOL).

In the medical context, QOL is often defined in terms of functional status (Guyatt et al., 1997). The concept of QOL presented here, however, is multidimensional, encompassing social, spiritual, and environmental aspects of life in addition to physical and psychological well-being (Edwards et al., 2002; Patrick et al., 2002). Moreover, it provides a global evaluation of one's life that can be used to determine the subjective experience of living with a condition, affect planning for the future, and potentially affect acceptance and adherence to 
treatment. The following cross-cultural definition of QOL proposed by the World Health Organization QOL Group (Bonomi et al., 2000; World Health Organization QOL Group, 1994) guided this research: QOL is "the individuals' perceptions of their position in life in the context of the culture and value systems in which they live, and in relation to their goals, expectations, standards, and concerns."

Long-term outcome studies of adults with congenital FDs have reported a negative effect on marital and financial/job status (Nash, 1995). Likewise, studies emphasizing objective outcomes have demonstrated that adolescents with FDs are at increased risk for problems in learning, behavior, and social competence (Tobiasen and Speltz, 1996). Results from a variety of studies exploring self-concept (Kapp-Simon, 1986; Broder and Strauss, 1989; Leonard et al., 1991), adjustment (Padwa et al., 1991), self-perception (King et al., 1993), and behavioral difficulties (Sarimski, 2001) among children with varying degrees of facial disfigurement and types of cleft and palate disorder, however, have yielded very mixed results. Studies on facial burns have shown that patients report increases in family socializing and a decrease in socializing with nonfamily members, especially when the burn survivor is male (Patterson et al., 1993). In addition, detriments in self-esteem have been noted among women and youth with severe burns, although the majority of burn victims have moderate to high levels of self-esteem (Bowden et al., 1980).

To understand the relation between FDs and the QOL of adolescents, this study compared self-reported QOL of adolescents (11-18 years old) with a diverse set of FDs with the selfreported QOL of adolescents with nonfacial visible differences, specifically mobility limitations (ML); invisible differences, specifically attention-deficit/hyperactivity disorder (ADHD); and with no diagnosed chronic conditions (NCC). Similar to adolescents with FDs, adolescents with ML such as spina bifida and cerebral palsy, and adolescents with ADHD (both with and without comorbid conditions), often experience stigma because they are perceived by others as being "different," which in turn may affect their QOL. The comparisons with adolescent groups with both visible and nonvisible differences may provide insight into whether stigma differentially affects the perceptions of QOL among adolescents with visible and nonvisible differences. Likewise, comparisons with a no-condition group can provide information on the efficacy of treatments (Patrick and Deyo, 1989) for adolescents with FDs in restoring a life of quality undifferentiated from those without the condition (Wallander et al., 2001).

\section{Methods}

\section{Participants}

Fifty-six adolescents with FDs were recruited from the Craniofacial Center at Children's Hospital and Regional Medical Center in Seattle, Washington, and from the Burn Center at the University of Washington, Harborview Medical Center, from March 2000 through May 2001. During a routine follow-
TABLE 1 Sample Breakdown by Condition and Gender

\begin{tabular}{lcc}
\hline \multicolumn{1}{c}{ Condition } & Males & Females \\
\hline Acquired conditions (burns, gunshot, severe acne) & 6 & 3 \\
Branchial arch disorders & 2 & 3 \\
Isolated or syndromic disorders and other conditions & & \\
$\quad$ (including ectodermal dysplasias, frontonasal dyspla- & & \\
$\quad$ sias, port wine stains, CHARGE syndrome) & 5 & 13 \\
Cleft lip/palate & 17 & 7 \\
Total & 30 & 26 \\
\hline
\end{tabular}

up visit at the centers or during a telephone call follow-up, patients were given a brief overview of the study (including an estimate of the time commitment) and were invited to be involved in the study by a clinician directly involved in their care. Permission for a study recruiter to contact them by telephone was obtained from interested adolescents and their caregivers. A telephone screening interview was conducted with interested caregivers for the purpose of confirming that the adolescent met the inclusion criteria: 11-18 years old with one of a number of craniofacial conditions or an acquired facial difference and able to speak and read English at the fifth-grade level. Adolescents with acquired FDs such as burn or trauma had to be at least 1 year post-initial presentation. Formal written informed consent/assent was obtained from all participants in the study, and the procedures were approved by the Institutional Review Board of Children's Hospital and Regional Medical Center, Seattle (CHRMC), and by the University of Washington. Table 1 shows the distribution of the FDs group by condition.

Adolescents in the ADHD ( $\mathrm{n}=68)$, ML $(\mathrm{n}=52)$, and NCC $(n=116)$ groups participated in an earlier study to validate the YQOL-R instrument (see Patrick et al., 2002). The recruitment period for these groups was March 1998 through January 2000. Adolescents in the ADHD group were recruited through two clinics specializing in the treatment of ADHD in the greater Seattle area. The ML group was recruited through CHRMC and through a community center. Adolescents in the NCC group were solicited from Seattle-area middle and high schools and via newspaper ads in local Seattle newspapers with teens as a target audience. The process used to recruit these clinical participants was the same as that to recruit the group with FDs reported here.

Diagnosis and treatment verification forms were obtained from the clinicians for all adolescents with ADHD, 98\% of adolescents with FDs and ML, and 94\% of adolescents in the NCC group. The diagnosis and treatment verification form included primary diagnosis, coexisting mental/emotional conditions, other physical conditions, and physical or psychosocial treatment.

\section{Instruments}

Youth Quality of Life Instrument-Research Version (YQOL-R)

The YQOL-R (Edwards et al., 2002; Patrick et al., 2002; Topolski et al., 2002), the dependent measure for comparing 
the study groups, was designed for use by adolescents ages 11-18 years. It is divided into two self-contained sections, one containing 15 contextual items that can potentially be reported on by others, and one containing 41 perceptual items across the four domains-Self $(\mathrm{n}=14)$, Relationships $(\mathrm{n}=14)$, Environment $(n=10)$, and General Quality of Life $(n=3)$ that can be reported only by the adolescents themselves. The Sense of Self domain pertains to feelings about oneself, such as belief in self, being oneself, mental and physical health, and spirituality. The Social Relationships domain pertains to relations with others, including adult support, caring for others, family relations, freedom, friendships, participation, and peer relations. The Environment domain pertains to opportunities and obstacles in the adolescent's broader social and cultural milieu, including engagement and activities, good education, liking neighborhood, monetary resources, personal safety, and view of future. Finally, the General Quality of Life domain pertains to the adolescent's sense of how well his or her life is going overall, including enjoying life, feeling life is worthwhile, and being satisfied with one's life. YQOL-R scores are reported on a 100-point scale, with a higher score being indicative of better quality of life. A 5-point difference on the scale generally relates to a medium effect size (.5), as described by Cohen (1988).

The contextual items are observable indicators of one's position in life and cover such issues such as serious family arguments, missing out on activities because of physical or emotional problems, and being made to feel unwelcome because of how you look. These observable criteria provide a context for the assessment of QOL and indicate potential intervention areas.

A readability analysis conducted on the YQOL-R has confirmed that it is readable at the fourth-grade level. Psychometric analyses on the perceptual scales have yielded scores with acceptable internal consistency (Cronbach's alpha $=0.77$ to 0.96 ), reproducibility (ICCs $=0.74$ to 0.85 ), expected associations with other measured concepts, and ability to distinguish between known groups (for complete information on the psychometric validation of the instrument, see Patrick et al., 2002).

\section{Children's Depression Inventory (CDI)}

The CDI (Kovacs, 1985) is included as a covariate in comparing the study groups. Depression is an important variable to measure because there is an elevated risk of internalizing behavior problems (shyness, withdrawal, despondency) among adolescents with FDs (Harper et al., 1980; Richman, 1976; Tobiasen et al., 1992). The CDI has been validated for use by children and adolescents ages 7 to 18 years (Timbermont et al., 2004).

\section{Hypotheses}

On the basis of unpublished pilot work, it was hypothesized that adolescents with FDs would report a lower mean total
YQOL-R score than adolescents without chronic conditions. Because of the stigma associated with being different, it was also hypothesized that the mean total YQOL-R score reported by adolescents with FDs would be similar to the mean scores for adolescents with ML and adolescents with ADHD. Differences among the condition groups on the domain scores were explored, and the individual contextual items were used in separate analyses to determine whether there were areas of specific concern based on type of condition or whether the concerns were common to all adolescents.

\section{Data Analysis}

Descriptive statistics were completed for the combined FDs and validation study samples. A multivariate analysis of covariance (MANCOVA) was conducted to test the hypothesis that adolescents with FDs would report lower perceptual YQOL-R scores than adolescents with no diagnosed chronic condition and be similar to the other stigmatized groups. On the basis of previous research (Topolski et al., 2001; Patrick et al., 2002), the analysis controlled for the covariates of age, gender, and depressive symptomatology as assessed by the CDI. To determine which group means differed, the domain scores were also assessed using linearly independent pairwise comparisons on the estimated marginal means, with Bonferroni correction for multiple comparisons with the alpha level set at .025 .

The YQOL-R contextual items were reviewed for mean differences by group. Pairwise comparisons on the estimated marginal means with Bonferroni correction for multiple comparisons with the alpha level set at .05 were conducted.

\section{RESUlTS}

\section{Descriptive Statistics}

Demographics for the combined FDs and validation samples (Table 2) showed that the ethnic mix of the sample was representative of the Puget Sound region of Washington, from which the participants were recruited (U.S. Census Bureau, 2000). The NCC, ML, and FDs groups did not differ significantly from each other on age and sex of the participant. Participants in the ADHD group were younger, and all were male by design of the study, based on the relatively low prevalence estimates of ADHD among female adolescents in clinical setting.

Physicians were asked to complete a verification of diagnosis and treatment (past and current) form, which also included a rating of their assessment of the global severity of the youth's facial differences, which was a modified version of the Clinical Global Impressions scale (Guy, 1976). For the FDs group, physicians provided treatment information for 54 youth and facial severity ratings for 52 youth. Physicians reported that 47 of the youth previously had surgery for their condition, 4 had taken medication, 1 had received counseling, and 4 had not been treated. The four youth who had not re- 
TABLE 2 Sample Demographics by Study Group

\begin{tabular}{|c|c|c|c|c|c|}
\hline & $\begin{array}{c}\text { Total } \\
\text { Sample } \\
(n=278)\end{array}$ & $\begin{array}{c}\text { General } \\
\text { Popula- } \\
\quad \text { tion } \\
(n=102)\end{array}$ & $\begin{array}{c}C F C \\
(n=56)\end{array}$ & $\begin{array}{l}A D H D \\
(n=68)\end{array}$ & $\begin{array}{c}\text { Mobility } \\
\text { Disability } \\
(n=52)\end{array}$ \\
\hline \multicolumn{6}{|l|}{ Age group } \\
\hline $11-14$ & $37 \%$ & $40 \%$ & $48 \%$ & $46 \%$ & $12 \%$ \\
\hline $15-18$ & $73 \%$ & $60 \%$ & $52 \%$ & $54 \%$ & $88 \%$ \\
\hline \multicolumn{6}{|l|}{ Sex } \\
\hline Female & $33 \%$ & $41 \%$ & $46 \%$ & $0 \%$ & $44 \%$ \\
\hline Male & $67 \%$ & $59 \%$ & $54 \%$ & $100 \%$ & $56 \%$ \\
\hline \multicolumn{6}{|l|}{ Ethnicity } \\
\hline White & $81 \%$ & $76 \%$ & $77 \%$ & $90 \%$ & $85 \%$ \\
\hline Asian/Pacific Islander & $4 \%$ & $11 \%$ & $4 \%$ & $0 \%$ & $4 \%$ \\
\hline African-American & $5 \%$ & $4 \%$ & $2 \%$ & $4 \%$ & $4 \%$ \\
\hline Hispanic & $2 \%$ & $0 \%$ & $7 \%$ & $0 \%$ & $4 \%$ \\
\hline Other/Mixed & $7 \%$ & $9 \%$ & $9 \%$ & $6 \%$ & $4 \%$ \\
\hline $\begin{array}{l}\text { Lives with both biological } \\
\text { parents }\end{array}$ & $67 \%$ & $74 \%$ & $64 \%$ & $66 \%$ & $58 \%$ \\
\hline
\end{tabular}

ceived any treatment for their condition were in the burn group. All adolescents were at least 1 year postoperative; however, for 20 youth (nine with CLP, four with isolated syndromic craniosystoses, two with branchial arch disorders, one with a birth mark, two with facial tumors, one with a gunshot wound, and one with oral facial digital syndrome), physicians reported they were scheduled for a future surgery. Other currently scheduled treatments included medication, orthodontics, and speech therapy.

Physicians were asked to give a global rating of the severity of the facial difference (range: $1=$ normal, to $7=$ severely disfigured). The means, standard deviations, and 95\% confidence interval for the physician global assessment of facial difference severity ratings by type of facial difference are presented in Table 3. Among youth with congenital conditions, the ratings ranged from minimally disfigured to severely disfigured, and the range for the acquired groups was normal (four youths) to severely disfigured (one youth).

Physicians for the ML and the ADHD group also provided severity ratings of the youth's conditions. The mean severity ratings for the groups did not differ significantly (mean physician severity ratings for the groups were $\mathrm{ML}=3.5$; $\mathrm{ADHD}$ $=2.9$; and FD = 3.7).

To assess mean differences between the groups, a multivariate analysis of covariance was employed, with age, sex, and CDI depression score as covariates. The n's for the FDs, ML, and NCC groups were slightly smaller than the total sample size because of missing data on either the CDI or one of the YQOL domains. Bivariate correlations between the CDI and YQOL-R domain and total scores showed significant negative correlations ranging from -.49 on the YQOL-R environmental domain to -.58 on the YQOL-R total score. Controlling for these variables, a significant difference among the centroids for the four groups on the set of YQOL-R domain scores and total score (Wilks Lambda $=.652, F=8.123, p=.0001$ ) was found. As noted, pairwise comparisons with Bonferroni
TABLE 3 Physician Severity Ratings of Facial Difference

\begin{tabular}{|c|c|c|c|c|c|}
\hline \multirow[b]{2}{*}{ Condition } & \multirow[b]{2}{*}{$N$} & \multirow[b]{2}{*}{ Mean } & \multirow[b]{2}{*}{$S D$} & \multicolumn{2}{|c|}{$\begin{array}{l}\text { 95\% Confidence } \\
\text { Interval }\end{array}$} \\
\hline & & & & $\begin{array}{l}\text { Upper } \\
\text { Bound }\end{array}$ & $\begin{array}{l}\text { Lower } \\
\text { Bound }\end{array}$ \\
\hline Cleft lip/palate & 21 & 3.5 & 1.03 & 2.84 & 4.12 \\
\hline Isolated syndromic craniosynostoses & 8 & 4.4 & 0.92 & 3.34 & 5.41 \\
\hline Branchial arch disorders & 8 & 3.6 & 1.60 & 2.59 & 4.66 \\
\hline Birthmarks & 1 & 4.0 & $\dagger$ & 1.06 & 6.93 \\
\hline Facial tumors & 2 & 4.5 & 2.12 & 2.42 & 6.58 \\
\hline Acquired conditions & 7 & 2.7 & 2.21 & 1.60 & 3.83 \\
\hline Other & 5 & 4.2 & 2.05 & 2.89 & 5.51 \\
\hline Overall Mean & $52 *$ & 3.7 & 1.47 & 3.25 & 4.05 \\
\hline
\end{tabular}

* Physicians did not provide ratings for four youths.

$\dagger$ Only one youth with a birthmark was in the study; therefore, no standard deviation could be calculated.

correction for multiple comparisons were used to assess which means differed between the groups. The estimated marginal means (EMMs) adjusted for the covariates and 97.5\% confidence intervals are presented by domain and study group in Figure 1.

As shown in Figure 1, all condition groups reported significantly lower mean scores on the Environmental domain than their peers without chronic conditions. Adolescents with facial differences and ADHD reported significantly lower perceived QOL on the Self domain than did adolescents in the NCC group, and adolescents with ML and FDs reported significantly lower General QOL domain scores than did those with ADHD and no conditions.

To understand the differences between the groups on the domain scores, the constituent individual items were reviewed, with a Bonferroni correction for multiple comparisons applied. Item marginal means and $97.5 \%$ confidence intervals presented by domain are shown in Table 4 for the items for which means differed significantly. A review of the items making up the Self domain showed that youth with visible differences (ML and FDs) felt left out because of who they are more often than did the NCC, with a 17-point difference for the $\operatorname{ML}(p=.002)$ group and a 13-point difference for the FDs group $(p=.05)$. The difference in feeling left out between the ADHD group and the NCC group was 11 points $(p=.09)$. The scores reflect a 100 -point scale, so a 17 -point difference is equivalent to $17 \%$. The FDs group also reported that they felt significantly (alpha $=0.025$ ) less important to others, less likely to keep trying when at first they do not succeed, and less likely to report that their life has meaning $(p=.03)$.

In the Relationships domain, adolescents with FDs did not differ from the NCC group or adolescents with MLs. The ADHD group reported significantly lower scores than the NCC group. Looking at the individual items that make up the $\mathrm{Re}$ lationship domain, adolescents in the FDs group reported somewhat, although not significantly, higher scores than any of the other groups on being understood by their parents and feeling that their family encouraged them to do their best. In contrast, the adolescents with ADHD reported lower scores than the NCC group on all the items having to do with their 

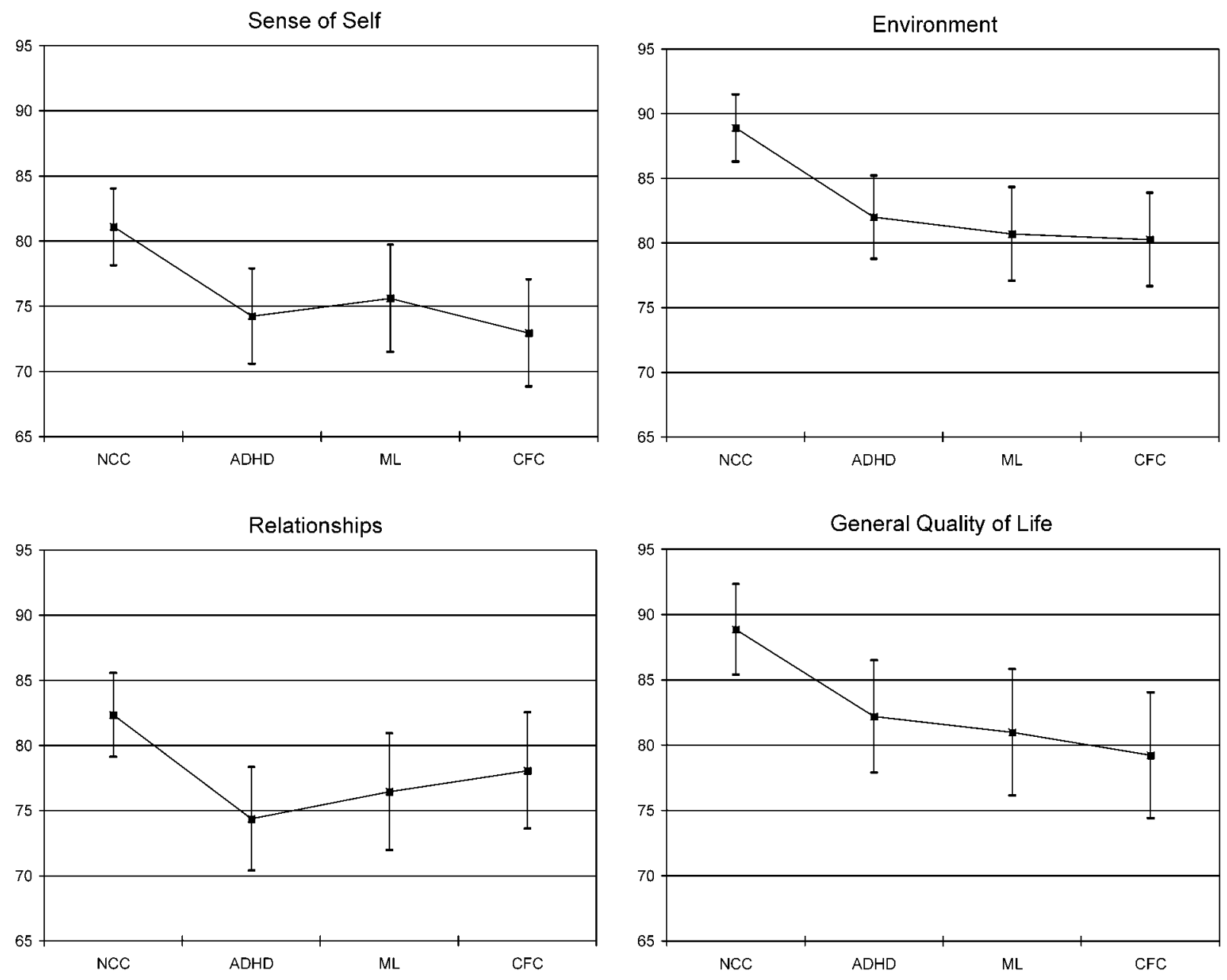

FIGURE 1 Estimated marginal means (EMM) adjusted for the covariates and $97.5 \%$ confidence intervals for the YQOL-R domains by study group (NCC—no diagnosed chronic condition, ADHD—attention deficit/hyperactivity disorder, ML—mobility limitations, FDs—facial differences).

family, although not all scores were significantly different. All the condition groups reported feeling like they were treated with respect by their peers less often than did the NCC group.

The Environmental domain also showed significant differences between the NCC group and the FDs group. The FDs group reported that they were less likely to get a good education, enjoy learning new things, feel safe at school, or look forward to the future. The ML group also reported that they were significantly less likely to feel safe when they are at school and were more likely to report that they did not like their neighborhood. The ADHD group only reported a significant difference from the NCC group on getting a good education at our stringent criteria of alpha $=0.025$, but they were significantly different at the lesser criterion of alpha $=0.05$ on knowing how to get the information they need and on enjoying trying new things.

On the General QOL domain, although all three condition groups reported scores lower than the NCC group, only the mean scores for the ML group and the FDS group were significantly lower $(p<.025)$. All three condition groups reported enjoying life significantly less than the NCC group. Adolescents in the ML and the FDs groups also reported feel- ing like life is worthwhile significantly less often. Effect sizes for the influence of group on the individual items ranged from $\eta^{2}=.04$ to $\eta^{2}=.13$.

The analysis of contextual items of the YQOL-R, using MANCOVA with controls for age, sex, and depressive symptomatology, showed that youth with FDs reported being made to feel unwelcome by their peers because of the way they look significantly more often than the NCC group, and they reported being in a good mood significantly less often than NCC group. Youth with FDs did not, however, report a difference on the other peer item-amount of time spent with a friend having a good time outside of school. There were no significant differences on the family-oriented contextual variables (dinner with parents, serious arguments among family members, or working around the house). In contrast, the ML group was significantly more likely than the NCC group to report missing out on an activity they wanted to do because of an emotional or physical problem, spending less time with friends outside of school having a good time, spending less time doing an activity they enjoy, and doing less work around the house. The ADHD group did not differ from the NCC group on any of the contextual items. 
TABLE 4 Difference in Estimated Marginal Means (EMM) for Significantly Different Contextual and Perceptual Items by Domain and Study Group

\begin{tabular}{|c|c|c|c|c|c|}
\hline & \multirow{2}{*}{$\begin{array}{c}\text { Group* } \\
\text { Comparison }\end{array}$} & \multirow{2}{*}{$\begin{array}{c}\text { EMM } \dagger \\
\text { Difference }\end{array}$} & \multirow[b]{2}{*}{$S E$} & \multicolumn{2}{|c|}{$97.5 \%$ Confidence Interval } \\
\hline & & & & Lower Bound & Upper Bound \\
\hline \multicolumn{6}{|l|}{ Self } \\
\hline \multirow[t]{3}{*}{ Keep trying } & NCC-FDs & 13.63 & 3.55 & 3.37 & 23.89 \\
\hline & ADHD-FDs & 12.97 & 3.86 & 1.82 & 24.11 \\
\hline & ML-FDs & 11.89 & 3.84 & 0.81 & 22.98 \\
\hline Handle difficulties & NCC-ML & 9.71 & 3.17 & 1.28 & 18.15 \\
\hline \multirow[t]{2}{*}{ Feel important to others } & NCC-FDs & 13.82 & 4.00 & 2.25 & 25.29 \\
\hline & NCC-ADHD & 14.19 & 3.68 & 3.54 & 24.83 \\
\hline Feel left out because of who I am $\ddagger$ & NCC-ML & 17.01 & 4.64 & 3.60 & 30.40 \\
\hline Feel my life has meaning & NCC-FDs & 10.91 & 3.87 & -0.26 & 22.09 \\
\hline Unwelcome because of looks & NCC-FDs & 14.95 & 4.26 & 3.63 & 26.28 \\
\hline \multicolumn{6}{|l|}{ Relationship } \\
\hline Adults encourage me do best & NCC-ADHD & 8.04 & 2.69 & 0.28 & 15.81 \\
\hline \multirow{2}{*}{ People my age treat me w/respect } & NCC-ADHD & 11.30 & 3.62 & 0.85 & 21.75 \\
\hline & NCC-FDs & 12.15 & 3.91 & 0.83 & 23.43 \\
\hline \multirow[t]{3}{*}{ I can take part in same activities } & NCC-ML & 26.01 & 4.05 & 14.31 & 37.71 \\
\hline & ADHD-ML & 17.32 & 4.66 & 3.86 & 30.79 \\
\hline & CFC-ML & 16.12 & 4.65 & 2.68 & 29.58 \\
\hline \multicolumn{6}{|l|}{ Environment } \\
\hline Like my neighborhood & $\mathrm{NC}-\mathrm{ML}$ & 15.49 & 4.66 & 2.03 & 28.94 \\
\hline Look forward to future & $\mathrm{NC}-\mathrm{FDs}$ & 11.83 & 3.43 & 1.92 & 21.74 \\
\hline \multirow{2}{*}{ Good education } & NCC-ADHD & 10.22 & 3.15 & 1.12 & 19.32 \\
\hline & NCC-FDs & 11.21 & 3.04 & 1.38 & 21.03 \\
\hline Enjoy learning new things & NCC-FDs & 10.01 & 3.19 & 0.80 & 19.22 \\
\hline \multirow[t]{2}{*}{ Safe at school } & NCC-ML & 11.29 & 3.53 & 1.09 & 21.49 \\
\hline & NCC-FDs & 13.83 & 3.74 & 3.02 & 24.63 \\
\hline \multicolumn{6}{|l|}{ General QoL } \\
\hline \multirow[t]{3}{*}{ Enjoy life } & NCC-ADHD & 8.54 & 2.91 & 0.14 & 16.94 \\
\hline & NCC-ML & 10.12 & 2.96 & 1.61 & 18.64 \\
\hline & NCC-FDs & 13.10 & 3.15 & 4.00 & 22.21 \\
\hline \multirow[t]{2}{*}{ Life is worthwhile } & NCC-ML & 10.37 & 2.94 & 1.77 & 18.97 \\
\hline & NCC-FDs & 10.57 & 3.18 & 1.37 & 19.76 \\
\hline Compared with others my age & NCC-ML & 13.45 & 3.55 & 3.19 & 23.71 \\
\hline My life is much better & NCC-FDs & 11.06 & 3.80 & 0.08 & 22.03 \\
\hline
\end{tabular}

\section{Discussion}

QOL information is vital to understanding adolescents' perspectives and satisfaction with living with facial differences. Equalizing the QOL that these adolescents experience with that of adolescents without facial differences is often the implied justification for many of the medical procedures these adolescents go through. The comparison of adolescents with FDs to peers with a ML, ADHD, or those without a diagnosed condition revealed both similarities and differences in the aspects that comprise their overall QOL. As hypothesized, youth with FDs reported a lower overall QOL score than their peers who did not have chronic conditions. Overall, their scores more closely resembled those of adolescents with other chronic conditions.

In the data on the four constituent domains of the YQOL$\mathrm{R}$, several differences emerged between the groups with a "visible difference" (FDS, Mobility) and the group whose condition is not reflected in a physical difference (ADHD). Most notable were the disparities in the relationship domain.
The groups with visible differences were similar to their peers without a chronic condition on the Relationship domain, whereas the ADHD group reported a significant difference. A closer review of the data, however, showed that the visibledifference groups reported lower scores than their no-condition peers on the variables that related to peer interactions. This was illustrated by the fact that the adolescents with FDs were more likely to report that they were made to feel unwelcome by their peers because of the way they looked. The slightly higher scores in the family variables may indicate that adolescents with visible differences rely on their families to help negotiate the many trials of adolescence and use these relationships to compensate for the lack of peer relationships. Parents of youth with FDs are often required to provide extraordinary levels of care to the child for many years. This, coupled with parental worry about the child's welfare, may promote parental overprotectiveness and age-excessive levels of child/ adolescent dependence on the parent (Speltz et al., 1994).

The ADHD group, however, reported a significantly lower total Relationship score, but the difference was mainly related 
to family variables. All three condition groups were more likely to report that they felt people their age treated them with less respect.

A noticeable difference was also observed in the Environmental/Cultural domain. Although all condition groups scored lower on this domain than the NCC, only the adolescents with visible differences reported feeling less safe at school. This may be a reflection of the fact that these adolescents are often "picked on" and teased or bullied on the basis of their appearance and reflective of their status of being stigmatized in society.

Generic measures are important in that they can capture differences between groups of youth with and without chronic conditions; however, these instruments may not be sufficiently sensitive to areas that are specific to condition groups to allow a complete understanding of how their condition affects their quality of life. As noted here, the generic YQOL-R was able to capture the disparities of youth with FDs and their peers both with and without chronic conditions. It did not capture the positive aspects that some youth with FDs reported in the qualitative interviews presented in the companion paper by Edwards et al., published in this issue, and noted by others (Broder, 2001; Eiserman, 2001; Kelton, 2001), who found that adults felt more able to handle difficulties and perceived themselves to be more understanding of others.

A grateful response to life circumstances has been reported to be an adaptive psychological strategy and an important process by which people positively interpret everyday experiences (Emmons and McCullough, 2003). These youth may not have learned the coping skill necessary to bring about this sense of positive self, or it may be that they have not yet matured to the point at which they can look back and get a sense that having a facial difference has helped to shape them into the individual they are, resulting in a positive sense of self.

Resilience has been defined as "the process of healthy human development-a dynamic process in which personality and environmental influences interact in a reciprocal, transactional relationship" (Benard, 1996, p. 9). Adolescents who overcome adversity, manifesting resilience despite the odds against them, typically have access to three sources of "protection": a cohesive and stable family, external support, and certain personal resources (Garmezy, 1988). The latter includes the following: personality assets such as self-esteem and autonomy; intellectual skills such as problem-solving abilities; social skills such as cooperation, social engagement, and responsiveness; a sense of self-efficacy; and an easygoing temperament (Garmezy, 1988). Although personality attributes cannot be taught; social skills training may be an effective way of helping adolescents with FDs improve their QOL.

There are several limitations to the results reported here. First, the data came from convenience samples of youth both with and without disabilities and may not reflect the general population of youth. Second, the sample sizes for the condition groups were small, and although the effects of age and gender were statistically adjusted, larger samples with an equal number of boys and girls and equal distributions of age across the groups are needed to confirm the results reported here. Third, as noted above, the generic measure used here may not have enough items regarding family and peers to sufficiently capture the complete picture of how these factors affect the QOL of youth with FDs.

Finally, all condition groups were highly heterogeneous, which may limit the generalizability of results to any one condition. Combining youth with both acquired and congenital conditions is a severe limitation of the study, and we do not suggest that the effect on QOL of an acquired versus a congenital difference is exactly the same. The generic YQOL-R instrument, however, is designed to pick up between-group differences, whereas a condition-specific instrument such as the YQOL-FD is designed to pick up within-group differences.

QOL constitutes an important outcome for evaluating how facial differences and their treatment affect adolescents' lives. Generic measures permit comparisons between diverse groups but may be inadequate to get at specific concerns of the individuals within a condition group. A multisite study using this generic instrument and two newly developed craniofacial specific modules (described in a companion paper by Edwards et al.) is currently underway. It will be interesting to see whether the results from this important study will reflect similar findings to those reported here.

Acknowledgments. This work was supported by grant R01 DE13546-01 from the National Institute of Dental and Craniofacial Research. The findings from this article were presented at the American Cleft Palate-Craniofacial Association April 2003 Meeting held in Asheville, N.C.

\section{REFERENCES}

Benard B. From research to practice. Resiliency Action. 1996;1:7-11.

Bonomi AE, Patrick DL, Bushnell DM, Martin M. Validation of the United States' version of the World Health Organization Quality of Life (WHOQOL) instrument. J Clin Epidemiol. 2000;53:19-23.

Bowden ML, Feller I, Tholen D, Davidson TN, James MH. Self-esteem of severely burned patients. Arch Phys Med Rehab. 1980;61:449-452.

Broder HL. Using psychological assessment and therapeutic strategies to enhance well-being. Cleft Palate Craniofac J. 2001;38:248-254.

Broder H, Strauss RP. Self-concept of early primary school children with visible or invisible defects. Cleft Palate Craniofac J. 1989;26:114-117.

Cohen J. Statistical Power Analysis for Behavioral Sciences. 2nd ed. New York: Academy Press; 1988.

Cole J. About Face. Cambridge, MA: MIT Press; 1998.

Edwards TC, Huebner CE, Connell FA, Patrick DL. Adolescent quality of life, part I: Conceptual and measurement model. J. Adolesc. 2002;25:275-286.

Eiserman W. Unique outcomes and positive contributions associated with facial difference: expanding research and practice. Cleft Palate Craniofac J. 2001; 38:236-244.

Emmons RA, McCullough ME. Counting blessings versus burdens: an experimental investigation of gratitude and subjective well-being in daily life. $J$ Personality Social Psychol. 2003;84:377-389.

Garmezy N. Stressors in childhood. In: N Garmezy and M Rutter, eds. Stress, Coping and Development in Children. Baltimore, MD: Johns Hopkins University Press; 1988:43-84.

Guy W. ECDEU Assessment Manual for Psychopharmacology, Revised. DHHS Publication ADM 91-338. Rockville, MD: US Department of Health and Human Services, 1976.

Guyatt GH, Naylor CD, Juniper E, Heyland DK, Jaeschke R, Cook DJ. Users' 
guides to the medical literature: XII. How to use articles about health-related quality of life. J Am Med Assoc. 1997;277:1232-1237.

Harper DC. Children's attitudes to physical differences among youth from western and non-western cultures. Cleft Palate Craniofac J. 1995;32:114-119.

Harper DC, Richman LC, Snyder BC. School adjustment and degree of physical impairment. J Pediat Psychol. 1980;5:377-382.

Harper DC, Wacker DP, Cobb LS. Children's social preferences towards peers with visible physical differences. J Pediat Psychol. 1986;11:323-342.

Kapp-Simon K. Self-concept of primary-school-age children with cleft lip, cleft palate, or both. Cleft Palate J. 1986;23:24-27.

Kapp-Simon KA, Simon DJ, Kristovich S. Self-perception, social skills, adjustment and inhibition in young adolescents with craniofacial anomalies. Cleft Palate Craniofac J. 1992;29:352-356.

Kelton RW. Facing up to stigma: workplace and personal strategies. Cleft Palate Craniofac J. 2001;38:245-247.

King GA, Schultz IZ, Steel K, Gilpin M, Cathers T. Self-evaluation and selfconcept of adolescents with physical disabilities. Am J Occupational Ther. 1993;47:132-140.

Kovacs M. The Children's Depression Inventory (CDI). Psychol Bull. 1985;21: 995-998.

Leonard BJ, Boust JD, Abrahams G, Sielaff B. Self-concept of children with cleft lip and/or palate. Cleft Palate Craniofac J. 1991;28:347-353.

McQuaid D, Barton J, Campbell EA. Body image issues for children and adolescents with burns. J Burn Care Rehab. 2000;21:194-198.

Nash P. Living with Disfigurement: The Psychosocial Implications of Being Born with a Cleft Lip and Palate. Aldershot: Avebury; 1995.

Padwa BL, Evans CA, Pillemer FC. Psychosocial adjustment in children with hemifacial microsomia and other craniofacial deformities. Cleft Palate Craniofac J. 1991;28:354-359.

Patrick DL, Edwards TC, Topolski TD. Adolescent quality of life, part II: initial validation of a new instrument. J Adolesc. 2002;25:287-300.

Patrick D, Deyo RA. Generic and disease-specific measures in assessing health status and quality of life. Med Care. 1989;27(Suppl 3):S217-S232.

Patterson DR, Everett JJ, Bombardier CH, Questad KA, Lee VK, Marvin JA.
Psychological effects of severe burn injuries. Psychol Bull. 1993;113:362378.

Richman LC. Behavior and achievement of the cleft palate child. Cleft Palate Craniofac J. 1976;13:4-10.

Sarimski K. Social adjustment of children with a severe craniofacial anomaly (Apert syndrome). Child Care, Health Dev. 2001;27:583-590.

Speltz ML, Greenberg MT, Endriga MC, Galbreath M. Developmental approach to the psychology of craniofacial anomalies. Cleft Palate Craniofac J 1994; 31:61-67.

Timbermont B, Braet C, Dreessen M. Assessing depression in youth: relation between the Children's Depression Inventory and a structured interview. $J$ Clin Child Adolesc Psychol. 2004;33:149-157.

Tobiasen JM, Perkins A, Weaver J, Hiebert JM. Incidence of psychological adjustment problems in children and adolescents with cleft lip and palate. Presented at the 49th Annual Meeting of the American Cleft Palate-Craniofacial Association, Portland, OR, 1992.

Tobiason J, Speltz ML. Cleft palate: a psychosocial developmental perspective. In: Berkowitz E, ed. Cleft Lip and Palate: Perspectives in Management, Vol. 2. San Diego, CA: Singular; 1996:15-23.

Topolski TD, Patrick DL, Edwards TC, Huebner CE, Connell FA, Mount KK. Quality of life and health-risk behaviors among adolescents. J Adolesc Health. 2001;29:426-435.

Topolski TD, Edwards TC, Patrick DL. User's Manual and Interpretation Guide for the Youth Quality of Life (YQOL) Instruments. Seattle: University of Washington, 2002.

U.S. Census Bureau. 2000 Census Lookup. Available at: http://www.census. gov/. Accessed: June 2004.

Wallander JL, Schmitt M, Koot HM. Quality of Life measurement in children and adolescents: issues, instruments, and applications. J Clin Psychol. 2001; 57:571-585.

World Health Organization Quality of Life Group. The development of the World Health Organization Quality of Life Assessment Instrument (WHOQOL). In: Orley J, Kuyken W, eds. Quality of Life Assessment: International Perspectives. Berlin: Springer; 1994:41-57. 